\title{
CDC20 associated with cancer metastasis and novel mushroom-derived CDC20 inhibitors with antimetastatic activity
}

\author{
SHUJIE CHENG ${ }^{1,2}$, VICTOR CASTILLO ${ }^{2}$ and DANIEL SLIVA ${ }^{2-5}$ \\ ${ }^{1}$ Department of Food Quality and Safety, School of Engineering, China Pharmaceutical University, \\ Nanjing, Jiangsu 211198, P.R. China; ${ }^{2}$ Cancer Research Laboratory, Methodist Research Institute, \\ Indiana University Health; ${ }^{3}$ Department of Medicine, School of Medicine, Indiana University, \\ Indianapolis, IN 46202, USA, ${ }^{4}$ Department of Molecular Biology of Cancer, \\ Institute of Experimental Medicine, Czech Academy of Sciences, \\ 14220 Prague 4, Czech Republic; ${ }^{5}$ DSTest Laboratories, \\ Purdue Research Park, Indianapolis, IN 46241, USA
}

Received November 14, 2018; Accepted March 26, 2019

DOI: $10.3892 /$ ijo.2019.4791

\begin{abstract}
Aberrant expression of cell division cycle 20 (CDC20) is associated with malignant progression and poor prognosis in various types of cancer. The development of specific CDC20 inhibitors may be a novel strategy for the treatment of cancer with elevated expression of CDC20. The aim of the current study was to elucidate the role of CDC20 in cancer cell invasiveness and to identify novel natural inhibitors of $\mathrm{CDC} 20$. The authors found that $C D C 20$ knockdown inhibited the migration of chemoresistant PANC-1 pancreatic cancer cells and the metastatic MDA-MB-231 breast cancer cell line. By contrast, the overexpression of CDC20 by plasmid transfection promoted the metastasizing capacities of the PANC-1 cells and MCF-7 breast cancer cells. It was also identified that a triterpene mixture extracted from the mushroom Poria cocos (PTE), purified triterpenes dehydropachymic acid, and polyporenic acid C (PPAC) downregulated the expression of CDC20 in PANC-1 cells dose-dependently. Migration was also suppressed by PTE and PPAC in a dose-dependent manner, which was consistent with expectations. Taken together, the present study is the first, to the best of our knowledge, to demonstrate that CDC20 serves an important role in cancer metastasis and that triterpenes from $P$. cocos inhibit the migration of pancreatic cancer cells associated with CDC20. Further investigations are in progress to investigate the specific mechanism associated with CDC20
\end{abstract}

Correspondence to: Dr Daniel Sliva, DSTest Laboratories, Purdue Research Park, 5225 Exploration Drive, Indianapolis, IN 46241, USA

E-mail: dsliva@dstest-lab.com

Key words: cell division cycle 20, cancer metastasis, triterpenes, Poria cocos and these triterpenes, which may have future potential use as natural agents in the treatment of metastatic cancer.

\section{Introduction}

Cell division cycle 20 (CDC20), which was first identified in yeast in 1973, is critical in cell cycle progression (1). It activates the anaphase-promoting complex/cyclosome, thus modulating mitotic exit through the proteasomal degradation of proteins (2-4). Aberrant expression of CDC20 is associated with malignant progression and poor prognosis in various types of cancer, including pancreatic ductal adenocarcinoma, gastric cancer, urothelial bladder cancer, astrocytoma, hepatocellular carcinoma, lung adenocarcinoma and oral squamous cell carcinoma (5-11). In addition, there is a significant correlation between a high expression of CDC20 and advanced tumor stage in carcinoma of the breast, colon, endometrium and prostate (12-14). Therefore, CDC20 may be a promising therapeutic target for combating human cancer.

The most widely investigated functions of CDC20 are associated with cell cycle, proliferation and apoptosis (15). For example, there is an increase in cell cycle arrest at the G2/M phase and a decrease in the proliferation of hepatocellular carcinoma cells transfected with $C D C 20$ small interfering (si)RNA (16). CDC20 siRNA suppressed cell proliferation in vitro and growth of xenografted glioma cells in mice (17). Our previous study showed that a novel medicinal mushroom blend, ganodermanontriol, and a hydroxamic acid-derivative, 2-[benzyl-(2-nitro-benzenesulfonyl)-amino]-N-hydroxy-3-m ethyl-N-propyl-butyramide, suppressed the growth of breast cancer cells through the downregulation of CDC20 (18-20). Based on previous data, the focus of this study was on the novel function of CDC20 in cancer metastasis only.

Metastasis is the tendency of cancer cells to spread to distant organs, which is considered responsible for $>90 \%$ of cancer-associated mortality (21-24). It involves a multi-step process including migration from primary tumors, invasion to 
surrounding tissues and colonization in distant sites successfully $(21,24)$. However, the functional roles of CDC20 involved in the process of cancer metastasis remain to be fully elucidated.

In the present study, it was demonstrated that $C D C 20$ knockdown inhibited the migration of chemoresistant PANC-1 pancreatic cancer cells and metastatic MDA-MB-231 breast cancer cells (25). By contrast, the overexpression of CDC20 by plasmid transfection promoted the metastasizing capacities of PANC-1 and non-metastatic MCF-7 breast cancer cells (26). An identified triterpene mixture extracted from the edible and medicinal mushroom Poria cocos (PTE), purified triterpenes dehydropachymic acid (DPA) and polyporenic acid C (PPAC), downregulated the expression of CDC20 in PANC-1 cells dose-dependently. Migration was also suppressed by PTE in a dose-dependent manner, which was consistent with expectations. Taken together, it was demonstrated for the first time, to the best of our knowledge, that CDC20 serves an important role in cancer metastasis and that triterpenes from $P$. cocos inhibit the migration of pancreatic cancer associated with CDC20.

\section{Materials and methods}

Cell culture and reagents. The PANC-1 human pancreatic cancer cell line and MDA-MB-231 and MCF-7 breast cancer cell lines, obtained from American Type Culture Collection (ATCC, Manassas, VA, USA), were cultivated in Dulbecco's modified Eagle's medium (DMEM) containing penicillin $(50 \mathrm{U} / \mathrm{ml})$, streptomycin $(50 \mathrm{U} / \mathrm{ml}$; all Invitrogen; Thermo Fisher Scientific, Inc., Waltham, MA, USA), and $10 \%$ fetal bovine serum (FBS) from ATCC. DMSO was purchased from Sigma-Aldrich; Merck KGaA (Darmstadt, Germany). Anti-CDC20 (cat. no. sc-13162) and anti- $\beta$-actin (cat. no. sc-47778) antibodies were obtained from Santa Cruz Biotechnology, Inc. (Santa Cruz, CA, USA). Anti-FLAG M2 antibodies were from Sigma-Aldrich (Merck KGaA; cat. no. F3165).

Extraction and purification. Triterpenes were prepared from the pulverized sclerotium of $P$. cocos (Fujian, China). The method of preparation and identification follows as reported in our previous study (27). The quantification of HPLC analysis demonstrated that PTE contained $55.7 \%$ pachymic acid (PA), $31.7 \%$ DPA and $4.1 \%$ PPAC. The PTE, PA, DPA and PPAC were dissolved in DMSO at a concentration of $50 \mathrm{mg} / \mathrm{ml}$ and $50 \mathrm{mM}$, respectively and then stored at $-20^{\circ} \mathrm{C}$.

siRNA transfection. The PANC-1 or MDA-MB-231 cells were transfected with human CDC20 siRNA (cat. no. sc-156154) or control siRNA-A (cat. no. sc-37007) using siRNA Transfection Reagent (cat.no. sc-29528) from Santa Cruz Biotechnology, Inc. as previously described (27). CDC20 siRNA was used at $0.2 \mu \mathrm{M}$ and control siRNA-A was used at $0.9 \mu \mathrm{M}$. After $48 \mathrm{~h}$ at $37^{\circ} \mathrm{C}$ of transfection, the cells were harvested and $C D C 20$ knockdown was verified by western blot analysis.

DNA transfection. The FLAG-tagged plasmid DNA with CDC20 and FLAG-tagged plasmid DNA were provided by Professor Michele Pagano (NYU School of Medicine, New York, NY, USA). The PANC-1 or MCF-7 cells were transiently transfected with FLAG-tagged plasmid DNA with $C D C 20$ or control FLAG-tagged plasmid DNA using Lipofectamine $^{\mathrm{TM}}$ LTX Reagent according to the manufacturer's instructions (Invitrogen, Thermo Fisher Scientific, Inc.). After $24 \mathrm{~h}$ of transfection, the cells were harvested and the overexpression of CDC20 was verified by western blot analysis.

Western blot analysis. The sub-confluent (80-90\%) PANC-1 cells were treated with PTE (30 and $60 \mu \mathrm{g} / \mathrm{ml}$ ), PA (30 and $60 \mu \mathrm{M}$ ), DPA (30 and $60 \mu \mathrm{M})$, or PPAC (30 and $60 \mu \mathrm{M}$ ) for $24 \mathrm{~h}$ at $37^{\circ} \mathrm{C}$. Whole protein extracts isolated from cells were prepared using radioimmunoprecipitation assay buffer (Sigma-Aldrich; Merck KGaA). A total of $25 \mu \mathrm{g}$ protein per lane was separated on gels and transferred to a polyvinylidene difluoride (PVDF) membrane. The PVDF membrane was blocked with $5 \%$ bovine serum albumin (cat. no. A7906; Sigma-Aldrich; Merck KGaA) in Tris-buffered saline buffer with Tween-20 (TBTS) buffer for $1 \mathrm{~h}$ at room temperature, followed by the incubation of the anti-CDC20, anti-FLAG and anti- $\beta$-actin antibodies (diluted $1: 100$ ) overnight at $4^{\circ} \mathrm{C}$ as previously described (28). The PVDF membrane was then incubated with horseradish peroxidase-conjugated anti-mouse secondary antibodies (cat. no. NA-931; diluted 1:5,000; Amersham Biosciences, Buckinghamshire, UK) for $1 \mathrm{~h}$ at room temperature and protein expression was visualized by the ECL Plus Western Blotting Detection system (Amersham Biosciences). The western blots were scanned with HP Scanjet 5470c scanner (Hewlett Packard, Palo Alto, CA, USA) and the optical densities of proteins were quantified with UN-SCAN-IT software (version 7.0; Silk Scientific, Inc., Orem, UT, USA).

Cell migration assay. Cell migration of the PANC-1 cells treated with PTE (30 and $60 \mu \mathrm{g} / \mathrm{ml}$ ) or PPAC (30 and $60 \mu \mathrm{M})$ was assessed in Transwell chambers according to an established method (29). The PANC-1 cells $\left(0.2 \times 10^{6}\right)$ suspended in serum-free medium were added to the upper chamber of an insert, and the insert was placed in a 24-well plate containing medium with $10 \%$ FBS. The migration assays were performed for $24 \mathrm{~h}$ at $37^{\circ} \mathrm{C}$. Data points represent the mean \pm standard deviation (SD) of three individual filters within one representative experiment repeated at least twice. The changes in cell migration in the different cell lines were examined. For the metastatic MDA-MB-231 breast cancer cell line, migration can be evaluated following $3 \mathrm{~h}$ of incubation. For the migration of the non-metastatic MCF-7 human breast cancer cell line, incubation for $24 \mathrm{~h}$ is necessary (29).

Cell viability. Cell viability was determined following incubation with PTE (30 and $60 \mu \mathrm{g} / \mathrm{ml}$ ) or PPAC (30 and $60 \mu \mathrm{M})$ for $24 \mathrm{~h}$ by staining with Trypan blue $(0.4 \%)$ at $22^{\circ} \mathrm{C}$ for $5 \mathrm{~min}$. The cells were then viewed using an inverted light microscope at a magnification of $\mathrm{x} 40$, as previously described (30). This method is used to assess cytotoxicity in a variety of cell lines. Data are presented as the mean \pm SD from three independent experiments.

Statistical analysis. All statistical analyses were performed using GraphPad Prism 5 (GraphPad Software, Inc., San Diego, CA, USA). Data are presented as the mean \pm SD. Statistical 

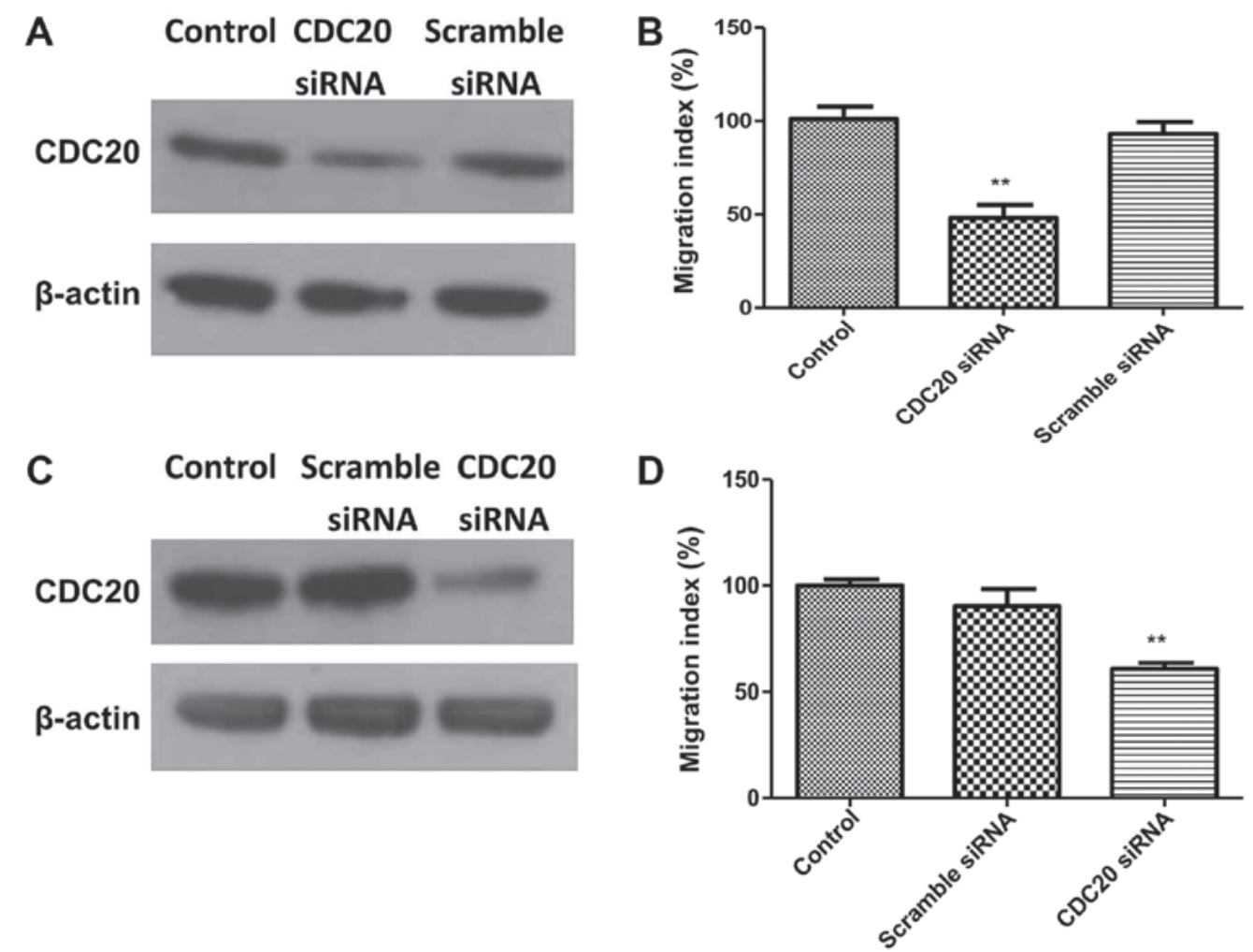

Figure 1. $C D C 20$ knockdown inhibits the migration of chemoresistant pancreatic cancer and metastatic breast cancer cells. PANC-1 cells and MDA-MB-231 cells were transfected with scrambled siRNA or CDC20 siRNA. (A) After $48 \mathrm{~h}$ of transfection, western blot analysis of CDC20 in PANC-1 cells was evaluated. (B) Migration of PANC-1 cells in Transwell chambers. (C) After $48 \mathrm{~h}$ of transfection, western blot analysis of CDC20 in MDA-MB-231 cells was evaluated. (D) Migration of MDA-MB-231 cells in Transwell chambers. Each bar represents the mean \pm standard deviation of three individual filters within one representative experiment repeated at least twice. ${ }^{* *} \mathrm{P}<0.05$ vs. Control. CDC20, cell division cycle 20; siRNA, small interfering RNA.

comparisons were performed using one-way analysis of variance with the significance level adjusted to $\mathrm{P}<0.05$ using repeated t-tests with the Bonferroni correction.

\section{Results}

CDC20 knockdown inhibits the migration of chemoresistant pancreatic cancer and metastatic breast cancer. To evaluate whether CDC20 was involved in the process of cancer metastasis, $C D C 20$ was silenced with siRNA as described above. As shown in Fig. 1A and B, the knockdown of $C D C 20$ effectively suppressed the migration of chemoresistant PANC-1 pancreatic cancer cells by $>40 \%$. In the metastatic MDA-MB-231 breast cancer cell line, $\sim 40 \%$ of cell migration was significantly inhibited by $C D C 20$ knockdown (Fig. $1 \mathrm{C}$ and D). These results indicate that $\mathrm{CDC} 20$ is an important target of cancer metastasis. However, the use of additional siRNAs is planned in future investigations to assess whether the inhibitory effects of siRNA CDC20 are not caused by the off-target effect.

Overexpression of CDC20 promotes the metastasizing capacities of pancreatic and breast cancer. In order to gain further insight into the functional role of CDC20 associated with cancer metastasis, FLAG-tagged plasmid DNA with $C D C 20$ was transfected into the PANC-1 cell line and MCF-7 breast cancer cell line, respectively, to induce the overexpression of CDC20. Induction of the expression of CDC20 markedly promoted the migration of PANC-1 and
MCF-7 cells compared with the control (Fig. 2A-D). By contrast, transfection with FLAG-tagged plasmid DNA had no effect on cell migration, showing that promotion of the metastasizing capacities of pancreatic and breast cancer was closely associated with CDC20. The use of a mutant CDC20 expression vector is planned in future investigations to further confirm the crucial role of $\mathrm{CDC} 20$ in cell migration.

Triterpenes from P. cocos downregulate the expression of CDC20inchemoresistantpancreaticcancerdose-dependently. As it is suggested that CDC20 serves an important role in cancer metastasis, the present study aimed to identify novel CDC20 inhibitors from natural compounds. The PANC-1 cells were treated with PTE (30 and $60 \mu \mathrm{g} / \mathrm{ml}$ ), a triterpene mixture extracted from $P$. cocos, or three triterpenes PA, DPA and PPAC (30 and $60 \mu \mathrm{M}$ ), which were purified from PTE, for $24 \mathrm{~h}$. Western blot analysis was then performed. As shown in Fig. 3, PTE suppressed the expression of CDC20 in PANC-1 cells dose-dependently. Among the purified triterpenes, PPAC was the most effective compound in downregulating the expression of CDC20, and DPA exerted moderate inhibition at a high dose. However, PA had no effect on the expression of CDC20. Different experimental methods resulted in different expression levels of CDC20 in the control PANC-1 cells. In Fig. 1, the endogenous expression of $\mathrm{CDC} 20$ was determined by CDC20 antibody. In Fig. 2, the overexpression of CDC20 was determined by FLAG antibody in cells which were transiently transfected with FLAG-CDC20 plasmid DNA. 

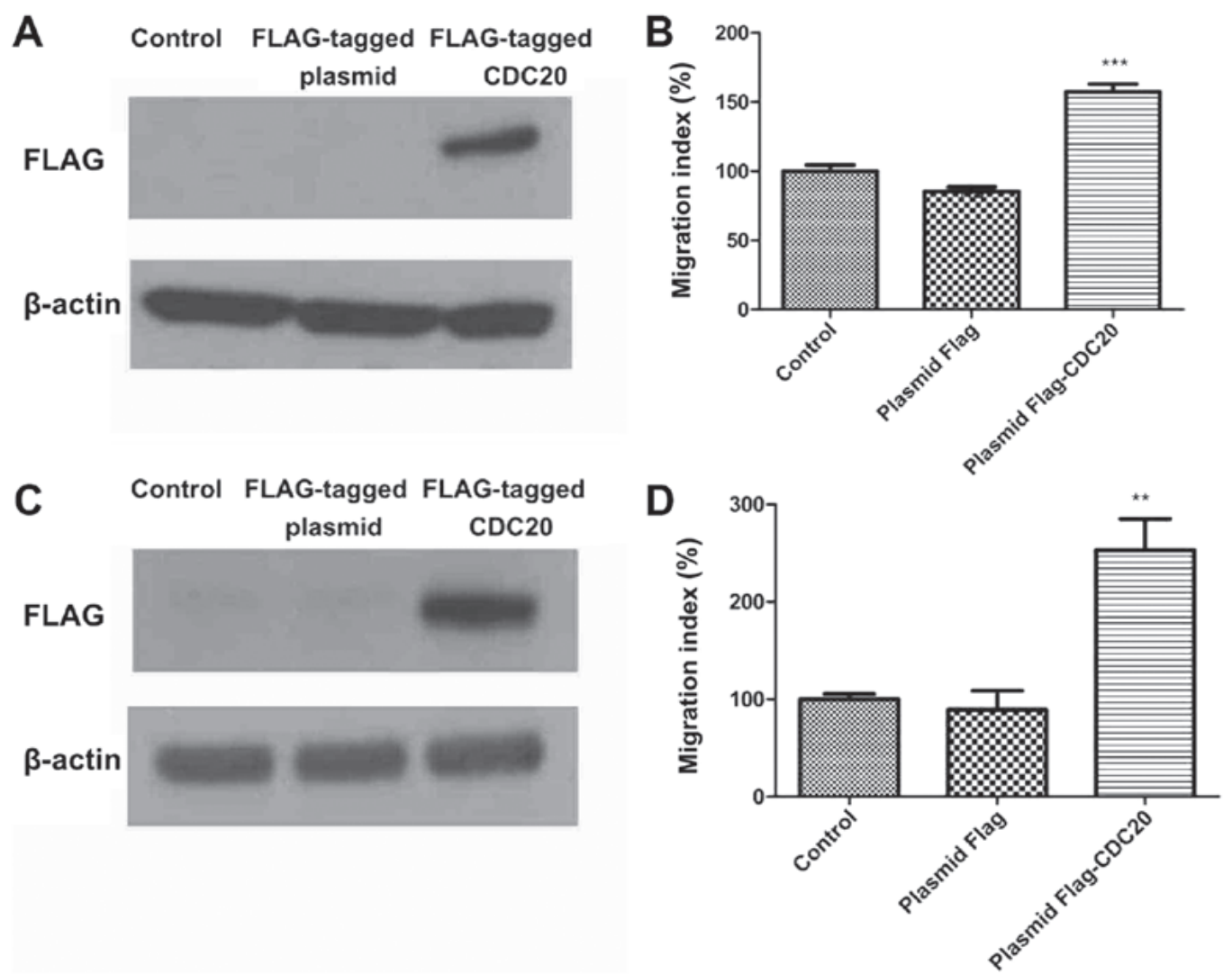

Figure 2. Overexpression of CDC20 promotes the migration of chemoresistant pancreatic cancer and breast cancer. PANC-1 cells and MCF-7 cells were transfected with FLAG-tagged plasmid DNA with CDC20 or FLAG-tagged plasmid DNA. (A) After $24 \mathrm{~h}$ of transfection, western blot analysis of CDC20 in PANC-1 cells was performed. (B) Migration of PANC-1 cells in Transwell chambers. (C) After $24 \mathrm{~h}$ of transfection, western blot analysis of CDC20 in MCF-7 cells was performed. (D) Migration of MCF-7 cells in Transwell chambers was determined. Each bar represents the mean \pm standard deviation of three individual filters within one representative experiment repeated at least twice. ${ }^{* *} \mathrm{P}<0.05$ and ${ }^{* * * *} \mathrm{P}<0.001$ vs. Control. CDC20, cell division cycle 20.

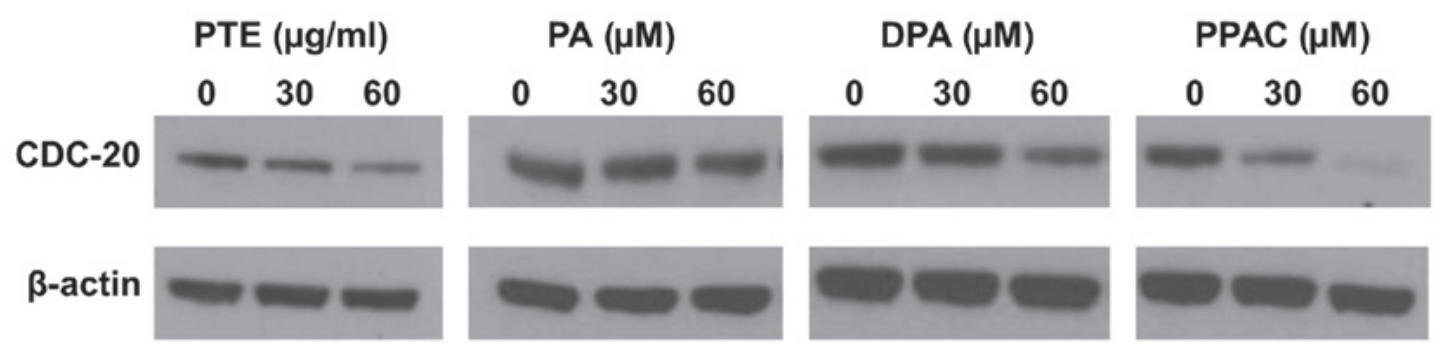

Figure 3. Effect of triterpenes from P. cocos on the expression of CDC20 in chemoresistant pancreatic cancer. PANC-1 cells were treated with PTE (30 and $60 \mu \mathrm{g} / \mathrm{ml})$, or PA $(30$ and $60 \mu \mathrm{M})$, DPA $(30$ and $60 \mu \mathrm{M})$ and PPAC $(30$ and $60 \mu \mathrm{M})$, three triterpenes purified from PTE for $24 \mathrm{~h}$, respectively. Whole protein extracts isolated from cells were prepared and western blot analysis with anti-CDC20 and anti- $\beta$-actin antibodies was performed. $\beta$-actin was used as a loading control. Representative images are shown. Similar results were obtained in at least two additional experiments. P. cocos, Poria cocos; CDC20, cell division cycle 20; PTE, triterpene mixture extracted from P. cocos; PA, pachymic acid; DPA, purified triterpenes dehydropachymic acid; PPAC, polyporenic acid C.

Therefore, the same cell line can exhibit different expression levels of CDC20.

Triterpenes from P. cocos suppresses the migration of chemoresistant pancreatic cancer in a dose-dependent manner. To determine whether the suppression of CDC20 by triterpenes from $P$. cocos is associated with the metastasizing capacities in chemoresistant pancreatic cancer, the PANC-1 cells were treated with PTE (30 and $60 \mu \mathrm{g} / \mathrm{ml})$ or PPAC (30 and $60 \mu \mathrm{M})$ for $24 \mathrm{~h}$ and cell migration was evaluated, as described above. In accordance with expectations, PTE (Fig. 4A and B) and PPAC (Fig. 5A and B) significantly inhibited the migration of the chemoresistant PANC-1 pancreatic cancer cells in a dose-dependent manner. The inhibition of cell migration was not caused by the toxic effects of the tested triterpenes, since PTE or PPAC did not affect the viability of PANC-1 cells (Figs. 4C and 5C). These results further demonstrated that triterpenes from $P$. cocos inhibited the migration of pancreatic cancer associated with CDC20. Although cell motility analysis in Transwell chambers is an established method to asses cell migration, a scratch assay and animal experiments will be performed in future experiments to verify these results in vitro and in vivo and to reduce the limitation of the present study. 

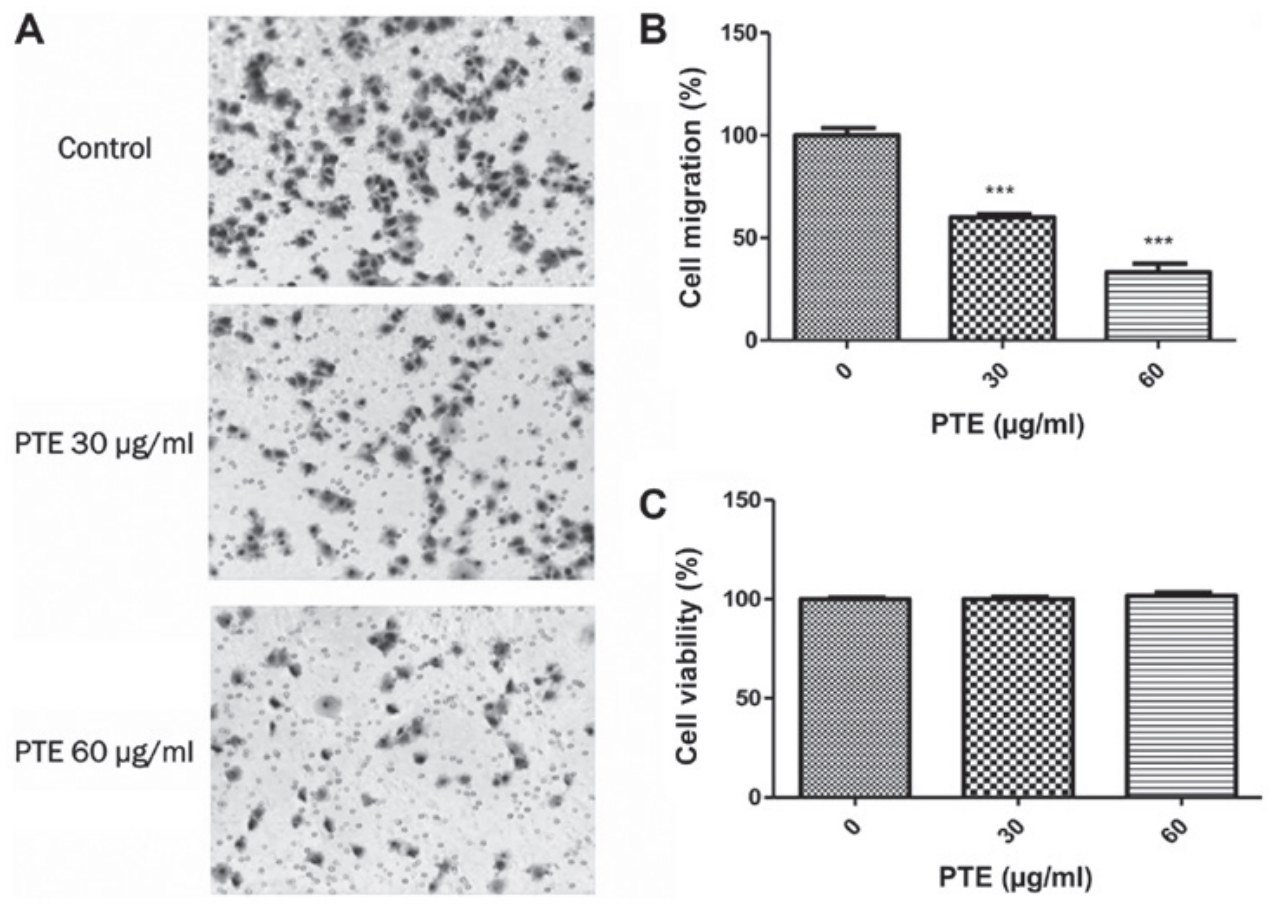

Figure 4. Effect of PTE on the migration of chemoresistant pancreatic cancer cells. PANC-1 cells were treated with PTE (30 and $60 \mu \mathrm{g} / \mathrm{ml})$ and cell migration in Transwell chambers was assessed. (A) Representative images of cell migration. Magnification, x40. (B) Quantification of migration; each bar represents the mean \pm SD of three individual filters within one representative experiment repeated at least twice. (C) Cell viability was determined; each bar represents the mean \pm SD of three experiments. Similar results were obtained in three independent experiments. ${ }^{* * *} \mathrm{P}<0.001$ vs. 0 PTE. PTE, triterpene mixture extracted from Poria cocos; SD, standard deviation.

A

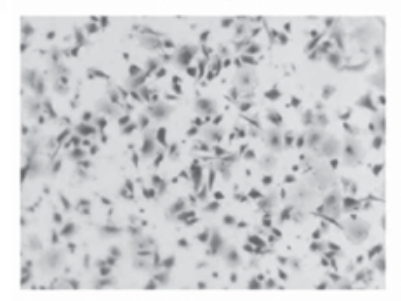

B

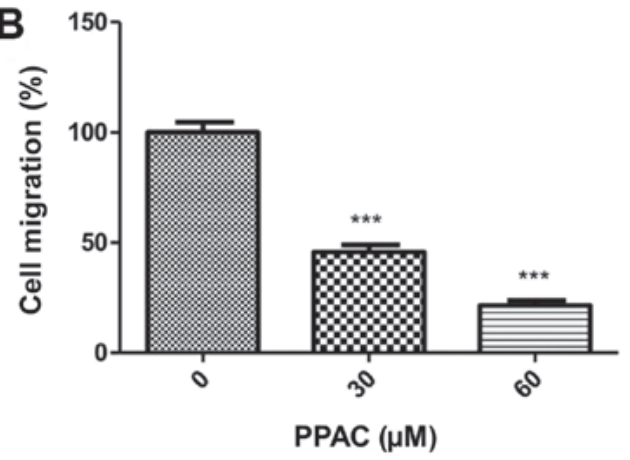

PPAC $30 \mu \mathrm{M}$

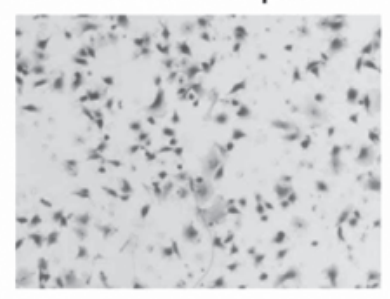

PPAC $60 \mu \mathrm{M}$

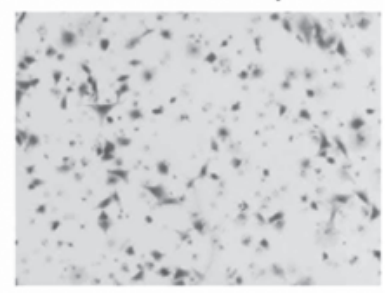

C

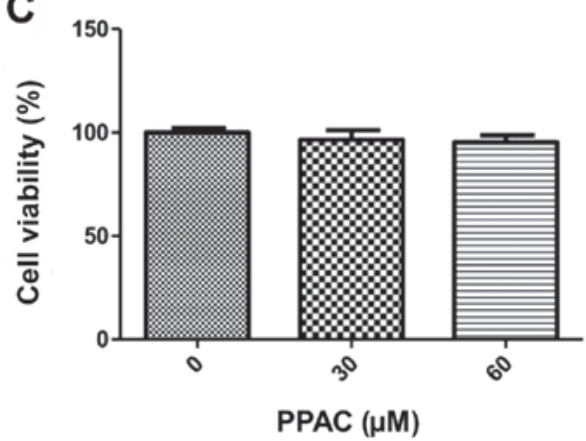

Figure 5. Effect of PPAC on the migration of chemoresistant pancreatic cancer. PANC-1 cells were treated with PPAC ( 30 and $60 \mu \mathrm{M})$ and cell migration in Transwell chambers was determined. (A) Representative images of cell migration are shown. Magnification, x40. (B) Quantification of migration; each bar represents the mean $\pm \mathrm{SD}$ of three individual filters within one representative experiment repeated at least twice. (C) Cell viability was determined; each bar represents the mean \pm SD of three experiments. Similar results were obtained in three independent experiments. ${ }^{* * *}$ P $<0.001$ vs. 0 PPAC. PPAC, polyporenicacid C; SD, standard deviation.

\section{Discussion}

A high expression of CDC20, a key component of the spindle assembly checkpoint, has been reported in various malignancies and serves a vital role in tumorigenesis and progression (13). It is reported that the silencing of $C D C 20$ suppresses metastatic castration-resistant prostate cancer growth and enhances chemosensitivity to docetaxel (31). Furthermore, the overexpression of CDC20 enhances cell proliferation and invasion in pancreatic cancer cells (32). The 
present study indicates for the first time, to the best of our knowledge, that $C D C 20$ knockdown inhibited migration, a key component of the tumor metastatic process, in chemoresistant pancreatic cancer cells and metastatic breast cancer cells. By contrast, the overexpression of CDC20 by plasmid transfection promoted the metastasizing capacities of these cells. These results suggest that $\mathrm{CDC} 20$ is a critical regulator of cancer metastasis. The underlying molecular mechanism of CDC20 may be associated with the tumor suppressor scaffold matrix attachment region binding protein 1 (SMAR1). Paul et al indicated that CDC20 is responsible for maintaining the cellular levels of SMAR1 in higher grades of cancer and that the CDC20-mediated proteasomal degradation of SMAR1 promotes cell migration and invasion (12).

Based on a number of studies, the development of specific CDC20 inhibitors may be a novel strategy for the treatment of cancer with elevated expression of CDC20 (33). Curcumin, a polyphenol derived from the Curcuma longa plant, exhibits its anticancer function through the inhibition of CDC20 in pancreatic cancer cells (32). P. cocos is an edible and medicinal mushroom of the Polyporaceae family, which is widely used as nutritious food, dietary supplements and traditional medicine in Asia (34,35). Increasing experimental evidence suggests that triterpenes isolated from $P$. cocos exert direct anticancer effects through a variety of mechanisms, including the inhibition of cell proliferation, induction of apoptosis and suppression of invasive behavior (36-40). In our previous study, PTE, PA, DPA and PPAC were found to inhibit the growth of pancreatic cancer cells in a dose-dependent manner. In addition, PTE and PA significantly suppressed the invasive behavior of the BxPc-3 pancreatic cancer cell line by inhibiting the expression of matrix metalloproteinase-7 (27). PA also suppresses growth and induces the apoptosis of chemotherapy-resistant pancreatic cancer cells in vitro and in vivo by targeting endoplasmic reticulum stress (41). In the present study, it was observed that PTE, DPA and PPAC downregulated the expression of CDC20 in chemoresistant pancreatic cancer cells dose-dependently. Migration was suppressed by PTE in a dose-dependent manner, which was in accordance with expectations.

In conclusion, the results of the present study indicate that CDC20 serves an important role in cancer metastasis and that triterpenes from $P$. cocos inhibit the migration of pancreatic cancer associated with CDC20. Further investigations are in progress to investigate the specific mechanism associated with CDC20 and these triterpenes, which may have potential for use as natural agents in the treatment of metastatic cancer.

\section{Acknowledgements}

The authors thank Professor Michele Pagano (NYU School of Medicine) for providing FLAG-tagged plasmid DNA with CDC20 and FLAG-tagged plasmid DNA, Dr Hui Xu (China Pharmaceutical University) for formatting figures and Mr. Petr Sliva (IU School of Medicine) for English editing.

\section{Funding}

This study was supported by grants from the National Key R\&D Program of China (grant no. 2017YFD0400203), the National Natural Science Foundation of China (grant no. 31701595) and the Natural Science Foundation of Jiangsu Province (grant no. BK20160750).

\section{Availability of data and materials}

All data generated or analyzed during this study are included in this published article.

\section{Authors' contributions}

SC performed and analyzed experiments, and wrote the manuscript. VC performed experiments. DS designed experiments, analyzed data and edited final version of the manuscript. All authors read and approved the final manuscript.

\section{Ethics approval and consent to participate}

Not applicable.

\section{Patient consent for publication}

Not applicable.

\section{Competing interests}

The authors declare that they have no competing interests.

\section{References}

1. Hartwell LH, Mortimer RK, Culotti J and Culotti M: Genetic control of the cell division cycle in yeast: V. Genetic analysis of cdc mutants. Genetics 74: 267-286, 1973.

2. Pines J: Cubism and the cell cycle: The many faces of the APC/C Nat Rev Mol Cell Biol 12: 427-438, 2011.

3. Primorac I and Musacchio A: Panta rhei: The APC/C at steady state. J Cell Biol 201: 177-189, 2013.

4. Singh GK, Karade SS, Ranjan R, Ahamad N and Ahmed S: C-terminal region of Mad2 plays an important role during mitotic spindle checkpoint in fission yeast Schizosaccharomyces pombe. Mol Biol Rep 44: 89-96, 2017.

5. Chang DZ, Ma Y, Ji B, Liu Y, Hwu P, Abbruzzese JL, Logsdon C and Wang $\mathrm{H}$ : Increased CDC20 expression is associated with pancreatic ductal adenocarcinoma differentiation and progression. J Hematol Oncol 5: 15, 2012.

6. Ding Y, Yu S, Bao Z, Liu Y and Liang T: CDC20 with malignant progression and poor prognosis of astrocytoma revealed by analysis on gene expression. J Neurooncol 133: 87-95, 2017.

7. Yan H, Li Z, Shen Q, Wang Q, Tian J, Jiang Q and Gao L: Aberrant expression of cell cycle and material metabolism related genes contributes to hepatocellular carcinoma occurrence. Pathol Res Pract 213: 316-321, 2017.

8. Jin X, Liu X, Li X and Guan Y: Integrated analysis of DNA methylation and mRNA expression profiles data to identify key genes in lung adenocarcinoma. BioMed Res Int 2016: 4369431, 2016.

9. Moura IM, Delgado ML, Silva PM, Lopes CA, do Amaral JB, Monteiro LS and Bousbaa H: High CDC20 expression is associated with poor prognosis in oral squamous cell carcinoma. J Oral Pathol Med 43: 225-231, 2014.

10. Ding ZY, Wu HR, Zhang JM, Huang GR and Ji DD: Expression characteristics of CDC20 in gastric cancer and its correlation with poor prognosis. Int J Clin Exp Pathol 7: 722-727, 2014.

11. Choi JW, Kim Y, Lee JH and Kim YS: High expression of spindle assembly checkpoint proteins CDC20 and MAD2 is associated with poor prognosis in urothelial bladder cancer. Virchows Arch 463: 681-687, 2013.

12. Paul D, Ghorai S, Dinesh US, Shetty P, Chattopadhyay S and Santra MK: Cdc20 directs proteasome-mediated degradation of the tumor suppressor SMAR1 in higher grades of cancer through the anaphase promoting complex. Cell Death Dis 8: e2882, 2017. 
13. Gayyed MF, El-Maqsoud NM, Tawfiek ER, El Gelany SA and Rahman MF: A comprehensive analysis of CDC20 overexpression in common malignant tumors from multiple organs: Its correlation with tumor grade and stage. Tumour Biol 37: 749-762, 2016.

14. Mao Y, Li K, Lu L, Si-Tu J, Lu M and Gao X: Overexpression of $\mathrm{Cdc} 20$ in clinically localized prostate cancer: Relation to high Gleason score and biochemical recurrence after laparoscopic radical prostatectomy. Cancer Biomark 16: 351-358, 2016.

15. Chen Z, Yu Y, Fu D, Li Z, Niu X, Liao M and Lu S: Functional roles of PC-PLC and Cdc20 in the cell cycle, proliferation, and apoptosis. Cell Biochem Funct 28: 249-257, 2010.

16. Li J, Gao JZ, Du JL, Huang ZX and Wei LX: Increased CDC20 expression is associated with development and progression of hepatocellular carcinoma. Int J Oncol 45: 1547-1555, 2014.

17. Xie Q, Wu Q, Mack SC, Yang K, Kim L, Hubert CG, Flavahan WA Chu C, Bao S and Rich JN: CDC20 maintains tumor initiating cells. Oncotarget 6: 13241-13254, 2015.

18. Jiang J and Sliva D: Novel medicinal mushroom blend suppresses growth and invasiveness of human breast cancer cells. Int J Oncol 37: 1529-1536, 2010.

19. Jiang J, Jedinak A and Sliva D: Ganodermanontriol (GDNT) exerts its effect on growth and invasiveness of breast cancer cells through the down-regulation of CDC20 and uPA. Biochem Biophys Res Commun 415: 325-329, 2011.

20. Jiang J, Thyagarajan-Sahu A,Krchňák V, Jedinak A, Sandusky GE and Sliva D: NAHA, a novel hydroxamic acid-derivative, inhibits growth and angiogenesis of breast cancer in vitro and in vivo. PLoS One 7: e34283, 2012.

21. Mehlen P and Puisieux A: Metastasis: A question of life or death Nat Rev Cancer 6: 449-458, 2006.

22. Nguyen DX and Massagué J: Genetic determinants of cancer metastasis. Nat Rev Genet 8: 341-352, 2007.

23. Monteiro $\mathrm{J}$ and Fodde R: Cancer stemness and metastasis: Therapeutic consequences and perspectives. Eur J Cancer 46: 1198-1203, 2010.

24. Deep G and Agarwal R: Antimetastatic efficacy of silibinin: Molecular mechanisms and therapeutic potential against cancer. Cancer Metastasis Rev 29: 447-463, 2010

25. Jin H, Lee WS, Eun SY, Jung JH, Park HS, Kim G, Choi YH, Ryu CH, Jung JM, Hong SC, et al: Morin, a flavonoid from Moraceae, suppresses growth and invasion of the highly metastatic breast cancer cell line MDA-MB-231 partly through suppression of the Akt pathway. Int J Oncol 45: 1629-1637, 2014.

26. Bajbouj K, Shafarin J and Hamad M: High-dose deferoxamine treatment disrupts intracellular iron homeostasis, reduces growth, and induces apoptosis in metastatic and nonmetastatic breast cancer cell lines. Technol Cancer Res Treat 17: 1533033818764470,2018

27. Cheng S, Eliaz I, Lin J, Thyagarajan-Sahu A and Sliva D: Triterpenes from Poria cocos suppress growth and invasiveness of pancreatic cancer cells through the downregulation of MMP-7. Int J Oncol 42: 1869-1874, 2013
28. Jiang J, Slivova V, Harvey K, Valachovicova T and Sliva D: Ganoderma lucidum suppresses growth of breast cancer cells through the inhibition of Akt/NF-kappaB signaling. Nutr Cancer 49: 209-216, 2004.

29. Lloyd FP Jr, Slivova V, Valachovicova T and Sliva D: Aspirin inhibits highly invasive prostate cancer cells. Int J Oncol 23: 1277-1283, 2003.

30. Sliva D, Jedinak A, Kawasaki J, Harvey K and Slivova V: Phellinus linteus suppresses growth, angiogenesis and invasive behaviour of breast cancer cells through the inhibition of AKT signalling. Br J Cancer 98: 1348-1356, 2008.

31. Li K, Mao Y, Lu L, Hu C, Wang D, Si-Tu J, Lu M, Peng S, Qiu J and Gao X: Silencing of CDC20 suppresses metastatic castration-resistant prostate cancer growth and enhances chemosensitivity to docetaxel. Int J Oncol 49: 1679-1685, 2016.

32. Zhang Y, Xue YB, Li H, Qiu D, Wang ZW and Tan SS: Inhibition of cell survival by curcumin is associated with downregulation of cell division cycle 20 (Cdc20) in pancreatic cancer cells. Nutrients 9: E109, 2017

33. Wang L, Zhang J, Wan L, Zhou X, Wang Z and Wei W: Targeting Cdc20 as a novel cancer therapeutic strategy. Pharmacol Ther 151: 141-151, 2015.

34. Wang M, Chen DQ, Chen L, Liu D, Zhao H, Zhang ZH, Vaziri ND, Guo Y, Zhao YY and Cao G: Novel RAS inhibitors poricoic acid ZG and poricoic scid ZH attenuate renal fibrosis via a Wnt/ $\beta$-catenin pathway and targeted phosphorylation of smad3 signaling. J Agric Food Chem 66: 1828-1842, 2018.

35. Miao H, Zhao YH, Vaziri ND, Tang DD, Chen H, Chen H, Khazaeli M, Tarbiat-Boldaji M, Hatami L and Zhao YY: Lipidomics biomarkers of diet-induced hyperlipidemia and its treatment with Poria cocos. J Agric Food Chem 64: 969-979, 2016.

36. Lai KH, Lu MC, Du YC, El-Shazly M, Wu TY, Hsu YM, Henz A, Yang JC, Backlund A, Chang FR, et al: Cytotoxic lanostanoids from Poria cocos. J Nat Prod 79: 2805-2813, 2016.

37. Jeong JW, Lee WS, Go SI, Nagappan A, Baek JY, Lee JD, Lee SJ, Park C, Kim GY, Kim HJ, et al: Pachymic acid induces apoptosis of EJ bladder cancer cells by DR5 up-regulation, ROS generation, modulation of Bcl-2 and IAP family members. Phytother Res 29: 1516-1524, 2015

38. Ríos JL: Chemical constituents and pharmacological properties of Poria cocos. Planta Med 77: 681-691, 2011.

39. Kikuchi T, Uchiyama E, Ukiya M, Tabata K, Kimura Y, Suzuki T and Akihisa T: Cytotoxic and apoptosis-inducing activities of triterpene acids from Poria cocos. J Nat Prod 74: 137-144, 2011.

40. Ling H, Zhang Y, Ng KY and Chew EH: Pachymic acid impairs breast cancer cell invasion by suppressing nuclear factor- $\kappa \mathrm{B}$-dependent matrix metalloproteinase-9 expression. Breast Cancer Res Treat 126: 609-620, 2011.

41. Cheng S, Swanson K, Eliaz I, McClintick JN, Sandusky GE and Sliva D: Pachymic acid inhibits growth and induces apoptosis of pancreatic cancer in vitro and in vivo by targeting ER stress. PLoS One 10: $\mathrm{e} 0122270,2015$. 